\title{
Comparison of Dynamic Stability Response of A SMIB with PI and Fuzzy Controlled DPFC
}

\author{
Budi Srinivasarao* $^{*}$, G. Sreenivasan ${ }^{2}$, Swathi Sharma ${ }^{3}$ \\ ${ }_{1,3}$ Jodhpur National University, Rajasthan, India \\ ${ }^{2}$ Intel Engineering College, Anathapur, A.P, India \\ e-mail: bsreee2013@gmail.com, gsn.anusree@gmail.com, er.swati.sharma15@gmail.com
}

\begin{abstract}
Consumer utilities are non -linear in nature. This injects increased flow of current and reduced voltage with distortions which cause adverse effect on the stability of consumer utilities. To overcome this problem we are using a modern Flexible Alternating Current Transmission System controller i.e. distributed power flow controller (DPFC). This controller is similar to UPFC, which can be installed in a transmission line between the two electrical areas. In DPFC, instead of the common Dc link capacitor three single phase converters are used. In this paper we are concentrating on system stability (oscillation damping). For analyzing the stability of a single machine infinite bus system (SMIB) we have used PI controlled Distributed Power Flow Controller (DPFC) and Fuzzy controlled DPFC. All these models are simulated using MATLAB/SIMULINK. Simulation results shows Fuzzy controlled DPFC are better than PI controlled $D P F C$. The significance of the results are better stability and constant power supply.
\end{abstract}

Keywords: PI, FUZZY, DPFC, dynamic stability, SMIB.

\section{Introduction}

Power quality means the interaction of electrical power with the electrical equipment. If the electrical equipment operates properly and reliably without being damaged or stressed, then we will say that the electrical power is of good quality. On the other hand, if the electrical equipment malfunctions or it is unreliable to operate or is damaged during normal usage, we can suspect that the power quality is poor.

The first sign of a power-quality problem is distortion in the voltage waveform of the power source from the reference wave i.e generally a sine wave, or in the amplitude from an established reference level, or a complete interruption. The distortion or the disturbance can be caused by the harmonics in the current or by events in the main voltage supply system.

The electrical power industry recognized the importance of power quality in power system stability is from 1920s onwards [1-2].

\section{Power System Stability}

It is the ability of an electric power system, for a given initial operating condition, to regain a state of operating equilibrium after being subjected to a physical disturbance [3-4], with most system variables bounded so that practically the entire system remains intact.

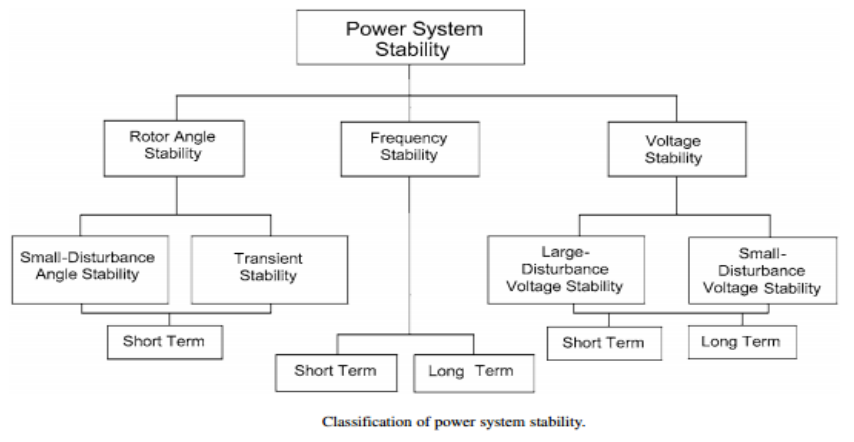

Figure 1. Classification of power system stability 


\subsection{Transient Stability}

It corresponds to the stability attained after a large mismatch. Suppose somewhere a fault occurs and suddenly a large part of load is bypassed. Then there is a large unbalance in the system. Then also gradually the system attains the stability.

\subsection{Dynamic Stability}

It is like transient stability but here help of an external device is taken to regain the stability whereas in transient stability the stability was attained within the power system itself without the help of any external device.

The usage of computer software simulation is gaining more popularity especially for the power system. It is appreciated that most of the computer software simulation studies require a Graphical User Interface (GUI) which makes the user interaction easier and more effective [5].

Simulink is particularly useful for studying the effects of nonlinearity on the behavior of the system, and as such, is also an ideal research tool. [6]

While transferring power from generation to consumer utility majority of problems at transmission line are Voltage and current variations. To overcome this sort of problems power electronic devices such as FACTS controllers like unified power flow controller (UPFC), STATCOM etc. are used. The present paper introduces a new device called Distributed power flow controller (DPFC).It is a combined converter i.e. it consists of both series and shunt converters. The shunt converter is similar to STATCOM, while the series converter implements the series connected DSSC concept. In DPFC multiple single-phase converters are used instead of one three-phase converter. Each converter involved in it is independent and has its own DC capacitor to provide the DC voltage needed. These converters will maintain the transmission line parameters such as bus voltage, line impedance and transmission angle within the range of normal of the power system.

\subsubsection{Consrtuction And Working of DPFC}

The DPFC structure is different from the other FACTS controllers especially with UPFC i.e the common DC link capacitor and 3rd order harmonic currents are used to exchange active power [8].

The DPFC consists of series and parallel connected converters. The parallel converter's operation is similar to that of a STATCOM, while the series converters implement the D-FACTS concept such as DVR. Each converter within the DPFC is independent and has a separate DC link capacitor to provide the required and sufficient DC voltage. Figure 2 shows the structure of a single machine system employed with DPFC technique. DPFC has the same control capability as that of the UPFC device. A process or the technique which allows exchange of active power between converters without having DC link is the prime requirement for DPFC [9]. Therefore, it allows exchanging the active power through the AC terminals of the converters.

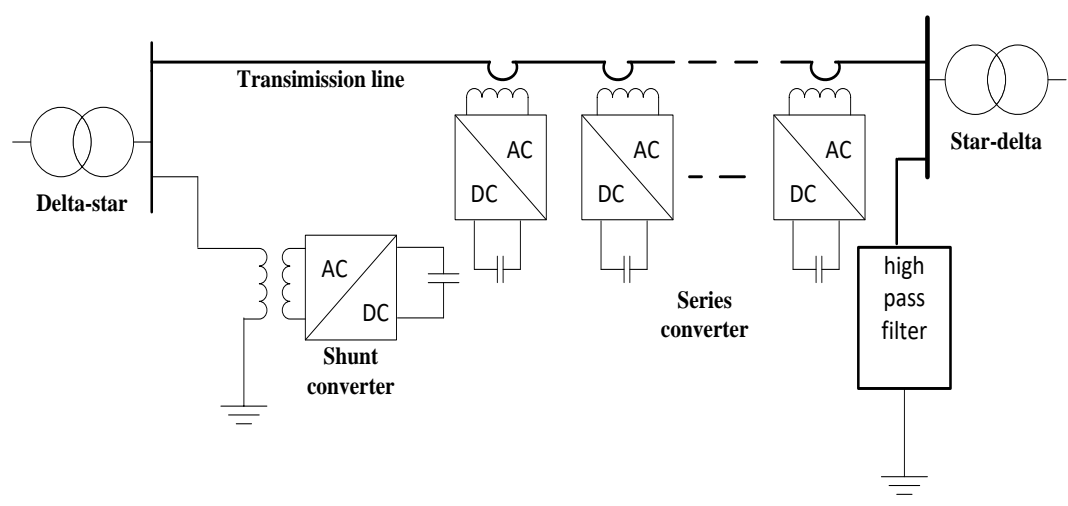

Figure 2. Fundamental circuit of DPFC

IJEEI Vol. 5, No. 3, September 2017: $199-206$ 


\subsection{Advantages Of DPFC}

The Distributed Power Flow Controller has the following advantages in comparison with UPFC, such as: It improves power quality. All power quality issues can be overcome by using FACTS devices.

1) More control capability: The DPFC can control all parameters of transmission line such as, transmission line impedance, load angle and transmission line voltage.

2) Higher efficiency: The series converters redundancy increases the DPFC reliability during converters operation [10-11]. It means, if one of series converters fails, the other series converters can continue to work.

3) Economical: Cost of DPFC is also less when compare to other FACTS devices which are used for voltage drop mitigation.

\subsubsection{DPFC Control Circuit}

Based on the following diagram the Distributed Power flow Controller has three types of controlling processes: [12] i.e., series controlling, Shunt controlling and central controlling.

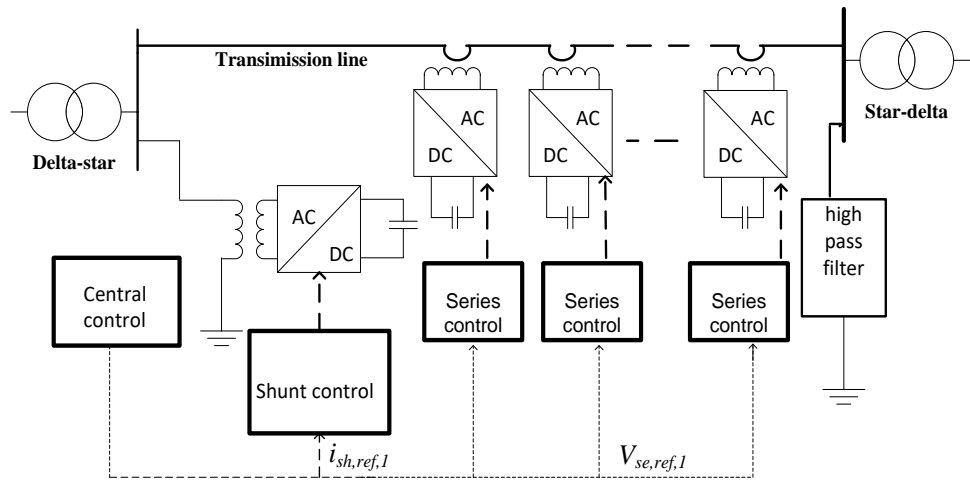

Figure 3. Control Diagram of DPFC

These three controllers are explained as follows:

a. Central Controller

The central controller is designed to control the three series controllers which are following DVR operation and the static shunt controllers by generating and feeding referral signals [13] (like series voltages and shunt currents) to the controllers in DPFC.

b. Series (voltage) Controller

The primary use need of this series controller is to maintain the voltage of capacitor and to generate series referral voltages at the natural frequency. This controller requires inputs from series capacitor. The line voltages and reference capacitor voltages are in direct and quadrature axis frame [14]. Generally, this series controller has first order low pass and third order band pass filters to create natural and 3rd order harmonic currents. The basic control structure for series controller is shown in Figure 4. 


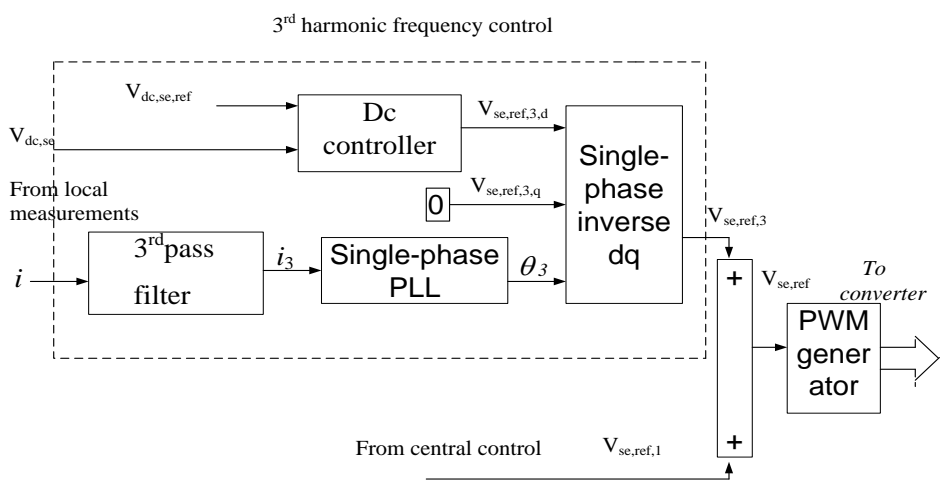

Figure 4. Basic structure of Series Controller

c. Shunt Current Controller

The basic control diagram of a shunt converter is shown in Figure 5. The Main purpose of the shunt controller is to inject 3rd harmonic currents into the transmission line to provide active power for the DVR (D-FACTS) converters [15]. The static converter is a three phase converter which is connected back to back with single phase converter. In this the three phase converter absorbs active power from supply grid and controls the output voltage of capacitor between these converters.

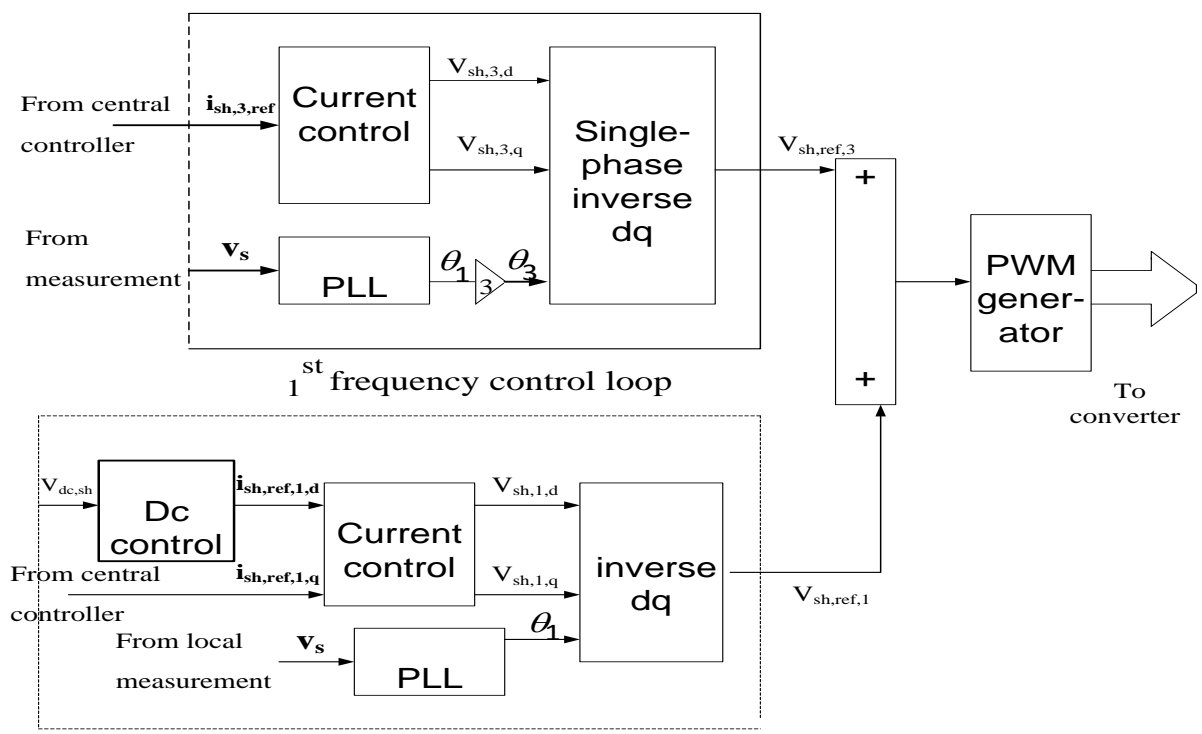

Figure 5. Basic Control Diagram of Shunt Controller

\subsubsection{Fuzzy Logic Controller}

Fuzzy set theory and fuzzy logic establish the rules of a non-linear mapping [16]. The use of fuzzy sets provides a basis for a systematic way for the application of uncertain and indefinite models. Fuzzy control is based on a logical system called fuzzy logic. It is much closer in spirit to human thinking and natural language than classical logical systems [17-18]. Nowadays, fuzzy logic is used in almost all sectors of industry and science. Some of the main aspects of fuzzy controller design are choosing the right inputs and outputs and designing each of the four components of the fuzzy logic controller 


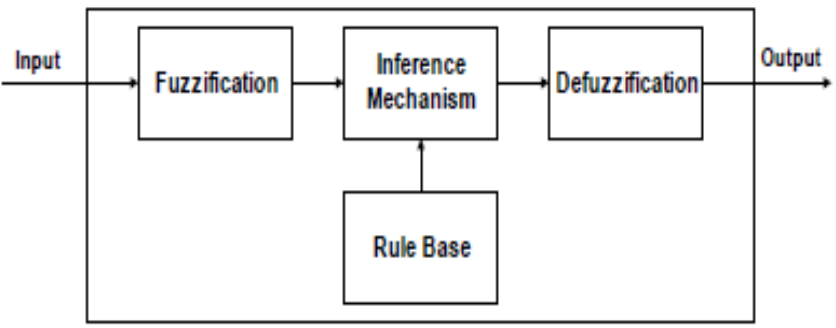

Figure 6. Active power exchange between DPFC converters

\subsubsection{Block Diagram}

In this paper, for a single machine infinite bus system dynamic stability analysis was done with PI and fuzzy controlled DPFC. Observations are shown below [19]. The simulation diagram was developed based on the basic diagram of DPFC, which is shown below in Figure 7.

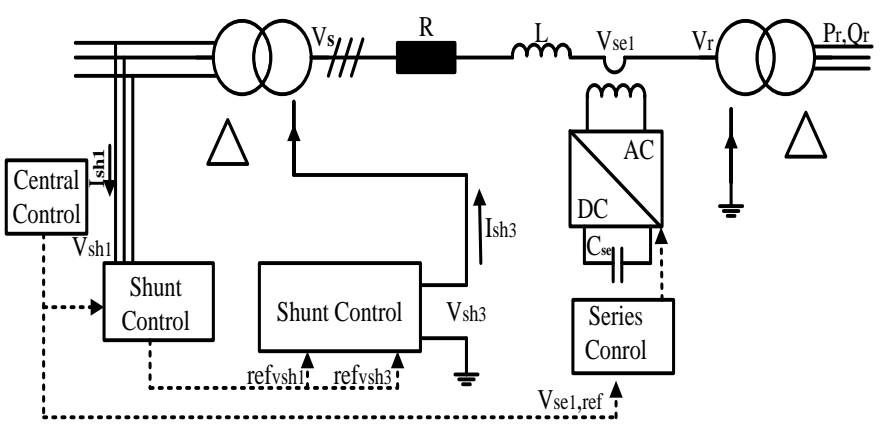

Figure 7. Structure of DPFC

\subsubsection{Simulatin Diagrams}

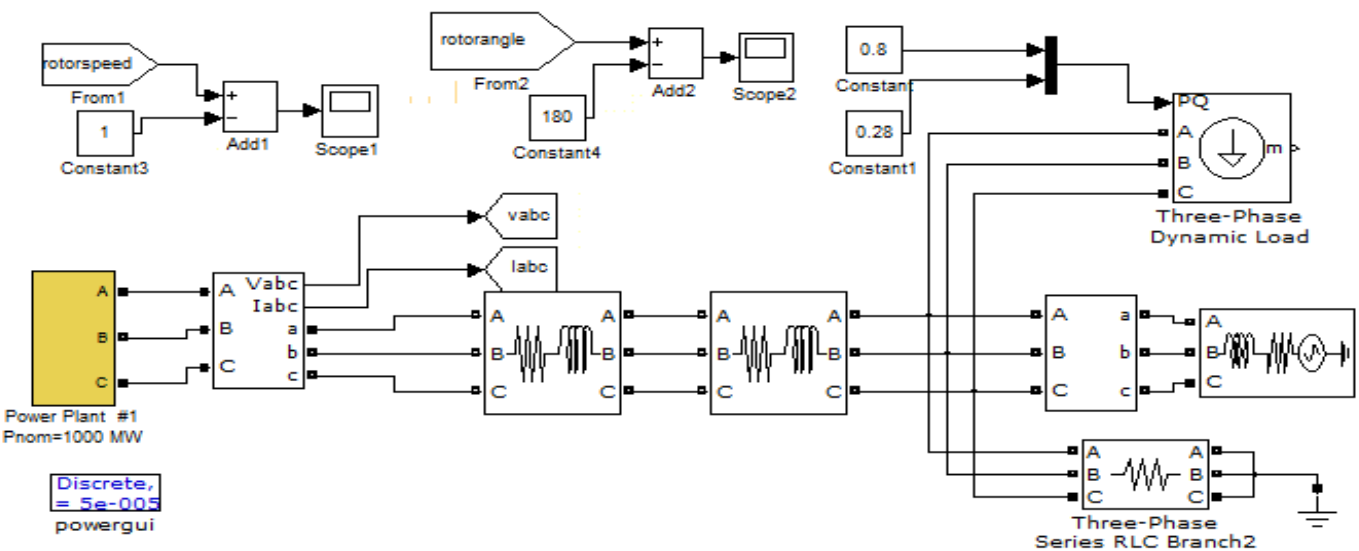

Figure 8. SMIB system without DPFC 


\subsubsection{Output waveforms}

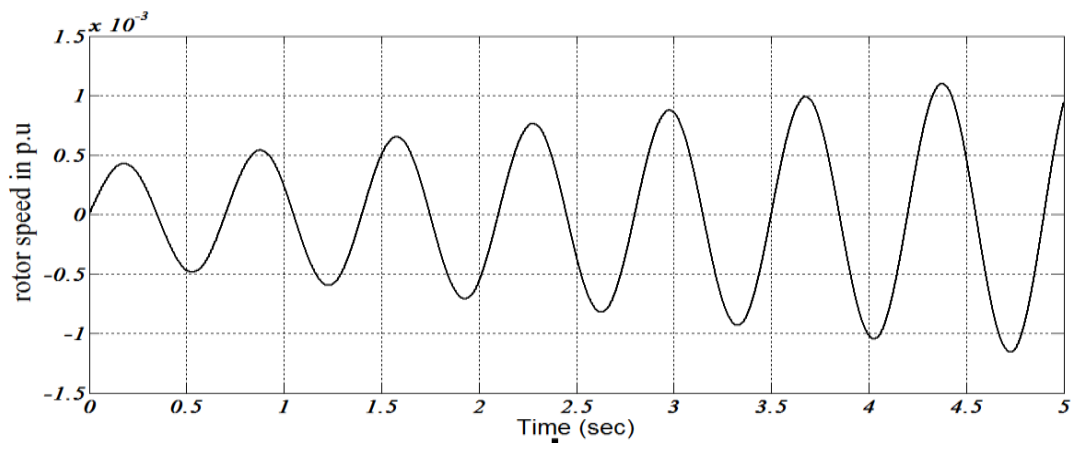

Figure 9. Rotor speed of SMIB system without DPFC

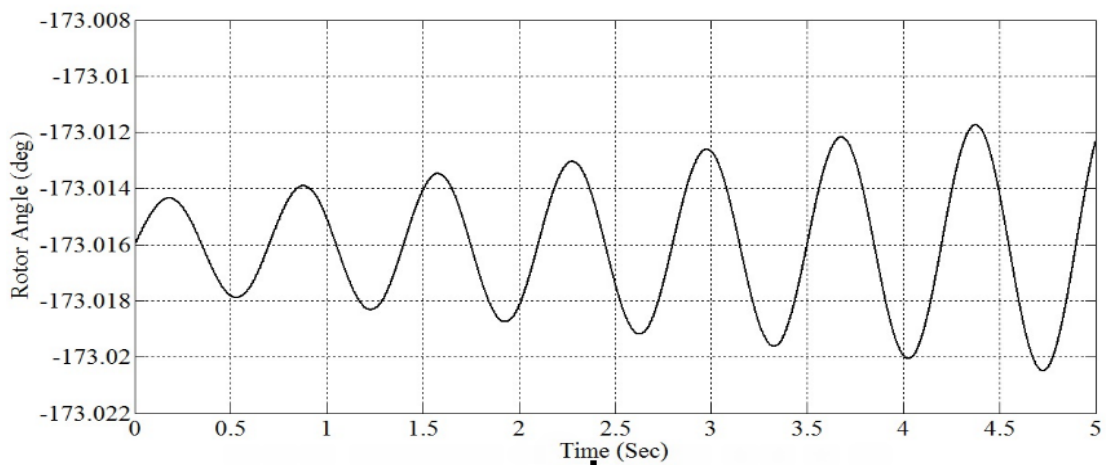

Figure 10. Rotor angle of SMIB system without DPFC

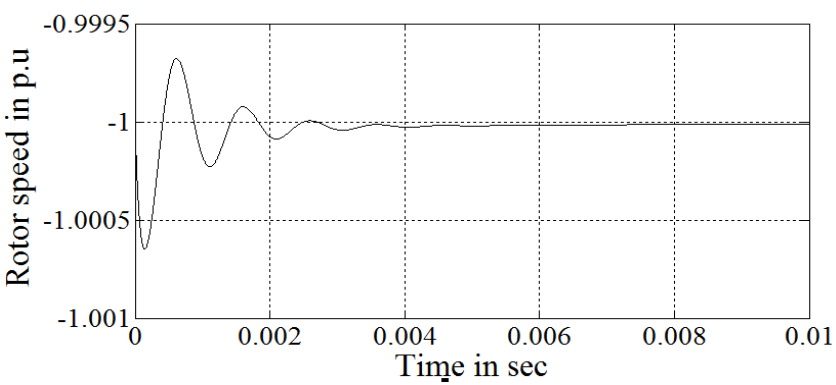

Figure 11. Rotor speed of SMIB system with DPFC (PI controlled)

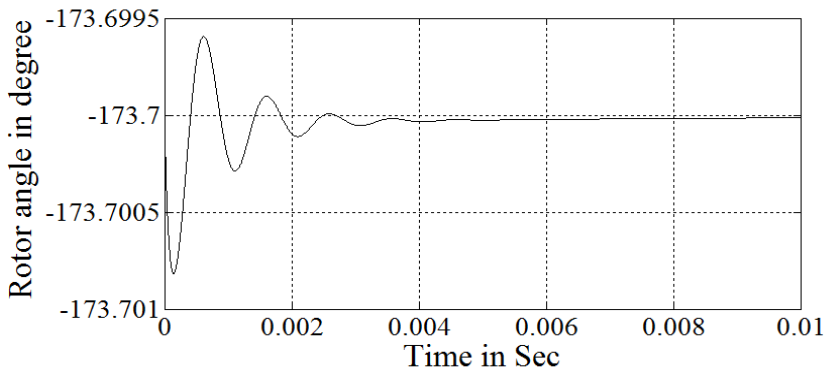

Figure 12. Rotor angle of SMIB system with DPFC (PI controlled) 


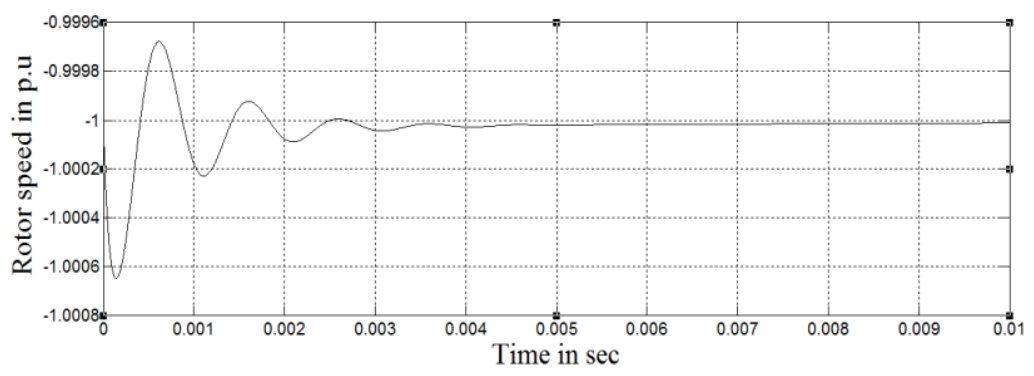

Figure 13. Rotor speed of SMIB system with DPFC (Fuzzy controlled)

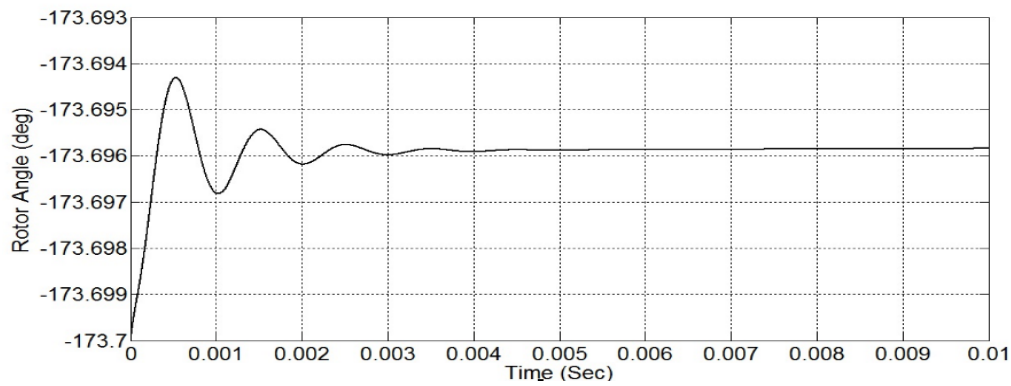

Figure 14. Rotor angle of SMIB system with DPFC (Fuzzy controlled)

\section{Conclusion}

In this paper we implemented a new concept for controlling power quality problems by using Distributed Power Flow Controller device. The proposed concept of the DPFC approach is mathematically formulated and analyzed for dynamic stability of a single machine and infinite bus system. The simulation results shows the effectiveness of DPFC in power system stability enhancement. Here we have implemented PI controlled DPFC and Fuzzy controlled DPFC to SMIB system and compared dynamic stability. From the waveforms we can observe that Fuzzy controlled DPFC is giving better dynamic stability than PI controlled DPFC.

\section{References}

[1] CP Steinmetz. Power control and stability of electric generating stations. AIEE Trans. 1920; 39(2): 1215-1287.

[2] AIEE Subcommittee on Interconnections and Stability Factors. First report of power system stability. AIEE Trans. 1926: 51-80.

[3] C Depcik, DN Assanis. Graphical user interfaces in an engineering educational environment, computer applications in engineering Education. 2005; 13: 48-59.

[4] W Long et al. EMTP a powerful tool for analyzing power system transients. IEEE Comput. Appl. Power. 1990; 3: 36-41.

[5] NG Hingorani, L Gyugyi. Understanding FACTS: Concepts and Technology of Flexible AC Transmission Systems. New York: IEEE Press. 2000.

[6] L Gyugyi, CD Schauder, SL Williams, TR Rietman, DR Torgerson, A Edris. The unified power flow controller: A new approach to power transmission control. IEEE Trans. Power Del. 1995; 10(2): 10851097.

[7] AA Edris. Proposed terms and definitions for flexible ac transmission system (facts). IEEE Trans. Power Del. 1997; 12(4): 1848-1853.

[8] KK Sen. Sssc-static synchronous series compensator: Theory, modeling, and application. IEEE Trans. Power Del. 1998; 13(1): 241-246.

[9] MD Deepak, EB William, SS Robert, K Bill, WG Randal, TB Dale, RI Michael, SG lan. A distributed static series compensator system for realizing active power flow control on existing power lines. IEEE Trans. Power Del. 2007; 22(1): 642-649. 
[10] D Diva, H Johal. Distributed facts-A new concept for realizing grid power flow control. in Proc. IEEE 36th Power Electron. Spec. Conf. (PESC). 2005: 8-14.

[11] Y Zhihui, SWH de Haan, B Ferreira. Utilizing distributed power flow controller (dpfc) for power oscillation damping. in Proc. IEEE Power Energy Soc. Gen. Meet. (PES), 2009: 1-5.

[12] Y Zhihui, SWH de Haan, B Ferreira. Dpfc control during shunt converter failure. in Proc. IEEE Energy Convers. Congr. Expo. (ECCE). 2009: 2727-2732.

[13] Y Sozer, DA Torrey. Modeling and control of utility interactive inverters. IEEE Trans. Power Electron. 2009; 24(11): 2475-2483.

[14] L Huber, BT Irving, MM Jovanovic. Review and stability analysis of pll-based interleaving control of dcm/ccm boundary boost pfc converters. IEEE Trans. Power Electron. 2009; 24(8): 1992-1999.

[15] Simon D. Design and Rule Base Reduction of a Fuzzy Filter for The Estimation of Motor Currents. Elsevier. International Journal of Approximate Reasoning. 2000; 25(2): 145-167.

[16] Song F, Smith SM. A Simple Weight Based Fuzzy Logic Controller Rule Base Reduction Method. IEEE International Conference on Systems, Man, and Cybernetics. 2000; 5: 3799-3799.

[17] Tao CW. A Reduction Approach for Fuzzy Rule Bases of Fuzzy Controller. IEEE Trans. on Systems, Man and Cybernetics Part B. 2002; 32(5): 668 - 675.

[18] M Mohaddes, AM Gole, S Elez. Steady state frequency response of statcom. IEEE Trans. Power Del. $2001 ; 16(1): 18-23$. 